\title{
Development of lithium-sulfur batteries using room temperature ionic liquid-based quasi-solid-state electrolytes
}

\author{
Atsushi Unemoto ${ }^{\mathrm{a}}$, Hideyuki Ogawa ${ }^{\mathrm{b}}$, Yoshiyuki Gambe ${ }^{\mathrm{b}}$, Itaru Honma ${ }^{\mathrm{b}, \mathrm{c}}$ \\ ${ }^{a}$ Advanced Institute for Materials Research (WPI-AIMR), Tohoku University \\ ${ }^{b}$ Institute of Multidisciplinary Research for Advanced Materials, Tohoku University \\ ${ }^{c}$ Corresponding author: i.honma@tagen.tohoku.ac.jp
}

\begin{abstract}
Quasi-solid-state electrolytes (QSEs), consisting of pseudo-ternary system, i.e., room temperature ionic liquid (RTIL)-lithium bis(trifluoromethanesulfonyl)amide (Li-TFSA)-fumed silica nano particles, were prepared for use as electrolytes in bulk-type all-solid-state cell configuration lithium-sulfur rechargeable batteries. Regardless of the high concentration of RTIL-Li-salt mixtures with fumed silica nano particles, i.e., 80-90\% volume ratio, the composites were white powders. Further blending with 5 wt \% polytetrafluoroethylene (PTFE) powder caused the composite powders to become transparent sheets of 30-200 $\mu \mathrm{m}$ in thickness. The electrolyte sheets exhibited liquid-like high apparent conductivities regardless of their solid-like appearance. Sulfur utilization ratios were enhanced using conductive additives with high specific surface areas. Cells with notable performance were successfully assembled after the optimization of the RTIL solvent composition, electrolyte thickness, and conductive additive species. The initial discharge capacity was $1100 \mathrm{mAh} \mathrm{g}^{-1}$ at $0.05 \mathrm{C}$. After 45 discharge-charge cycles, the discharge capacity was still $690 \mathrm{mAh} \mathrm{g}^{-1}$. This performance is comparable to lithium-sulfur cells that use the RTIL-Li-salt liquid electrolytes.
\end{abstract}

Keywords:

lithium-sulfur battery, bulk-type all-solid-state cell configuration, quasi-solid-state electrolyte (QSE), room temperature ionic liquids 


\section{Introduction}

To use rechargeable batteries for large-scale applications such as electric vehicles and load leveling, the enhancement of their energy density and improvements in their safety are important technological challenges. Therefore, the all-solid-state Li-S battery has attracted attention. The redox couple of Li-S has a higher theoretical capacity, $1672 \mathrm{mAh} \mathrm{g}^{-1}$, than conventional positive electrodes such as $\mathrm{LiCoO}_{2}$ and $\mathrm{LiFePO}_{4}$, which have capacities between 140 and $170 \mathrm{mAh} \mathrm{g}^{-1}[1,2]$. In addition, the solid-state electrolytes enable flexible device design that allows the enhance energy density.[3]

Ethers are recognized as the appropriate solvent that prevent from the reaction between the solvents and the reduced polysulfides contrary to carbonates and esters.[2, 4, 5] However, high solubility of lithium polysulfides in such solvents cause the loss of active materials into the electrolytes during battery operation, low coulombic efficiency because of polysulfide shuttle, and lithium electrode corrosion. [1, 6] The insulating nature of sulfur also lowers the sulfur utilization ratios. Thus, sulfur need to be effectively dispersed at the conductive additive surfaces and vice versa.

To overcome those issues, sulfur has been loaded into the interior of structured carbons, $[7,8,9,10,11]$ encapsulated by[12] and immobilized in[13] graphenes, and fixed on the side chain of polymers.[14, 15] Utilizations of inorganic solids[16, 17, 10, 11] and solid polymers[18, 19, 20], instead of organic liquid electrolytes in one possible measure for enhancing the cell performance. However, the number of solids that possess sufficient ionic conductivities, stability in the battery operating voltage range, and compatibility with electrodes is limited.[3, 21, 22]

The all-solid-state Li-S cells assembled with a thio-LISICON electrolyte require a $\mathrm{Li}-\mathrm{Al}$ alloy negative electrode, resulting in the low terminal voltage.[16, $10,11]$ The cell using $\mathrm{Li}_{2} \mathrm{~S}-\mathrm{P}_{2} \mathrm{~S}_{5}$ glass-ceramics electrolyte require the vacuum evaporation of the lithium negative electrode for a stable battery operation.[17] Li-S cells assembled with poly(ethylene oxide) (PEO)-based solid polymers require high operation temperatures such as 363 K.[18, 19] The all-solidstate Li-S cell assembled with a siloxane cross-linked polymer electrolytes is stable for a limited number of discharge-charge cycles.[20] A Li-S cell assembled with a microporous polymer membrane of poly(vinylidene fluoride- 
co-hexafluoropropylene) containing $1 \mathrm{M}$ lithium tetrafluoroborate and $1 \mathrm{M}$ lithium hexafluorophosphate in tetraetylene glycol dimethyl ether-ethylene carbonate requires high concentration of organic liquids. [23] All the individual systems described above have technological challenges. Therefore, to improve the Li-S battery performance, a design concept for a new battery configuration is necessary.

Using room temperature ionic liquids (RTILs) as electrolytes is preferable for Li-S cells because RTILs have attractive properties such as high ionic conductivity, wide potential windows, low vapor pressure, low flammability, and high stability. If electrolytes in lithium rechargeable batteries are replaced by RTILs, the assembly of safe Li-S batteries becomes possible. In addition, the low donor ability of RTILs[24, 25, 26] and glyme-Li-TFSA equimolar complex $[9,27]$ result in the low solubility of lithium polysulfides, and consequently, low solubility of lithium polysulfides realize the superior discharge-charge cycle performances.

Another interesting property of RTILs is their interaction with secondary media such as solid surfaces.[28, 29, 30,31, 29, 32, 33, 34, 35, 36, 37, 38, 39, $40,41,42,43]$ Highly ordered structures just beneath the charged sapphire substrate[35] and an anomalously enhanced viscosity within approximately $10 \mathrm{~nm}$ of the silica substrate[36] have been reported. In addition, high concentrations of RTILs can be confined at solid surfaces,[33, 34, 37, 38, 39, 40, $41,42,43]$ for instance, at $75-80 \%$ volume ratios when the RTIL-Li-salt is mixed in methanol with fumed silica nanoparticles of $7 \mathrm{~nm}$ diameter and $390 \mathrm{~m}^{2} \mathrm{~g}^{-1}$ specific surface areas.[33, 37, 38, 39, 40, 41, 42, 43] By using the quasi-solid-state electrolytes (QSEs) with high concentration of RTILs, lithium rechargeable batteries with bulk-type all-solid-state cell configurations have been assembled. As a result, when $\mathrm{LiCoO}_{2}$ and $\mathrm{Li}$ were used as the positive and negative electrodes, respectively, excellent charge-discharge performances were observed.[40, 41, 42]

Recently, Rao et al. assembled a Li-S battery using a porous carbon-sulfur positive electrode and $1 \mathrm{M}$ Li-TFSA in $N$-methyl- $N$-butylpyrrolidinium bis(trifluoromethanesulfonyl)amide (PYP14-TFSA)-poly(ethylene glycol) dimethyl ether (PEGDME) (1:1 by weight) electrolyte.[44] Despite the existence of high concentration of PEGDME, their cell realized a noticeable dischargecharge cycle performance since the micropores of the porous carbon work as 
trapping agents for the lithium polysulfides. This resulted in the prevention of the lithium polysulfide leakage into the electrolytes. As a result, despite a high concentration of sulfur in the composite positive electrode, $53.7 \%$ weight ratio, a noticeable increase in battery performance was observed, i.e., the 100th discharge capacity was $740 \mathrm{mAh} \mathrm{g}^{-1}$ at $0.05 \mathrm{C}$. Rao et al. also assembled a Li-S battery using a carbon nanofiber-sulfur positive electrode, and a gel polymer electrolyte consisting of a poly(acrylonitrile)/poly(methylmethacrylate) (PAN/PMMA) membrane immersed in $1 \mathrm{M}$ Li-TFSA in $N$-methyl- $N$-butylpiperidinium bis(trifluoromethanesulfonyl)amide (PP14-TFSA)-PEGDME (1:1 by weight).[45] Attributed to the prevention of the lithium polysulfides' dissolution into the gel electrolyte, the cell exhibited excellent performance, i.e., the 50th discharge capacity was $760 \mathrm{mAh}^{-1}$ at $0.1 \mathrm{C}$. However, there is still room for improvement in performances when the electrolyte only consists of a RTILLi-salt mixture.

This study aims to assemble a Li-S battery with a bulk-type all-solidstate cell configuration using the QSE consisting of RTILs-Li-lsat-fumed silica nanoparticles. To enhance the sulfur utilization ratios and achieve stable discharge-charge performances, carbon-sulfur positive electrodes were prepared. Carbons with different pore sizes distributions were examined in the Li-S cell assembly. The battery performances were evaluated as functions of the RTIL solvent, electrolyte sheet thickness, and conductive additive species.

\section{Experimental}

\subsection{Preparation of $Q S E$}

The ion structures of the RTILs examined in this study are shown in Fig. 1. Li-TFSA powder (99.9 \%, Kishida Chemical Co., Ltd.) was dissolved in 1-ethyl-3-methyl imidazolium bis(trifluoromethanesulfonyl)amide (EMITFSA, Kanto Chemical Co., Inc.), $N, N$-diethyl- $N$-methyl- $N$-(2-methoxyethyl)ammonium bis(trifluoromethanesulfonyl)amide (DEME-TFSA, Kanto Chemical Co., Inc.), and $N$-methyl- $N$-propyl piperidinium bis(trifluoromethanesulfonyl)amide (PP13TFSA, Kanto Chemical Co., Inc.) to create 1, 0.64 and $1 \mathrm{M}$ Li-salt solutions, respectively. Here 0.64 M Li-salt in DEME-TFSA was chosen, because the pseudo-binary system exhibited the highest limiting current[46] and excellent electrolyte performance for a $\mathrm{LiCoO}_{2}$ - $\mathrm{Li}$ cell[47]. The above chemicals were used as received and stored in an Ar-filled glove box. The mixed RTILsLi-TFSA solutions were further mixed in methanol with a powder of fumed 
silica nanoparticles (Sigma-Aldrich ${ }^{\circledR}$ ) of $7 \mathrm{~nm}$ diameter and $390 \mathrm{~m}^{2} \mathrm{~g}^{-1}$ specific surface area at $80 \%$ and $90 \%$ solvent volume ratios for at least $3 \mathrm{~h}$. The QSE powders were then recovered after evaporating methanol on a hot plate. The composition is denoted as $x$ vol\%Li-TFSA/cation-TFSA-fumed silica $(x=80$ and 90, and cation $=$ EMI, DEME, and PP13).

To obtain the self-supported electrolyte sheets, a powder of polytetrafluoroethylene (PTFE, Teflon6-J, Du Pont-Mitsui Fluorochemical Co., Ltd.) was mixed together with the QSE at a 5 wt\% weight ratio using an agate mortar and pestle. Here the $5 \%$ weight ratio represents the PTFE content. The QSE sheets were rolled out to a thickness of $200 \mu \mathrm{m}$ and $30 \mu \mathrm{m}$ for $x=80$ and 90, respectively, and then cut into discs of $12 \mathrm{~mm}$ diameter. The 200- $\mu$ m-thick QSE sheets were soaked in individual RTIL-Li-TFSA mixtures for conductivity evaluation and battery tests. The composition of the electrolyte sheets is denoted as $95 \mathrm{wt} \%(x$ vol\%Li-TFSA/cation-TFSA-fumed silica)-PTFE. All above procedures were carried out in an Ar-filled glove box.

\subsection{Measurements of viscosities and conductivities}

The viscosities of the RTIL solvents and RTIL-Li-salt mixtures were evaluated using a viscometer (DV-II+ Pro, Brookfield Engineering, Inc.) with a corn spindle (CPE-40) at $308 \mathrm{~K}$. The electrical conductivities of RTIL and RTIL-Li-salt, along with the apparent conductivities of the QSE, were evaluated by a two-probe ac technique using stainless-steel electrodes at $308 \mathrm{~K}$ with an electro-analytical system, VersaSTAT4 (Princeton Applied Research, Inc.).

\subsection{Preparation of positive electrodes and Li-S cell assembly}

In this study, the following three carbons were examined as the conductive additive: acetylene black (AB, FX35, Denki Kagaku Kogyo K. K.), Ketjen black (KB, EC600JD, Lion Corp.), and high surface area activated carbon, Maxsorb ${ }^{\circledR}$ (Kansai Coke and Chemicals Co., Ltd.). Sulfur was dispersed on the surfaces of conductive additives by melting diffusion using a previously reported method.[7] An elemental sulfur powder (reagent grade, Sigma-Aldrich ${ }^{\circledR}$ ) was mixed in desired ratios using an agate mortar and pestle, followed by annealing in Ar flow at $428 \mathrm{~K}$ for $6 \mathrm{~h}$. Nitrogen adsorptiondesorption isotherms were obtained for the conductive additives before and after sulfur dispersion by the Brunauer - Emmett - Teller (BET, Belsorp 18, BEL Japan, Inc.) measurements. Mesopore distributions of AB, KB, AB-S and KB-S were analyzed by the BJH method.[48] Micropore distributions of 
Maxsorb ${ }^{\circledR}$ and Maxsorb ${ }^{\circledR}$-S were analyzed by the MP method.[49]

The resultant powders were mixed together with quasi-solid-state composite powder and PTFE in an Ar-filled glove box.

The microstructures and element distributions of the composite positive electrode surfaces were investigated by field-emission scanning electron microscopy (FE-SEM, S-4100, Hitachi High-Technologies Corp.) and energydispersive X-ray spectrometry (EDS, Inca x-act, Oxford Instruments), respectively. X-ray diffraction (XRD) patterns of the elemental sulfur and conductive additive-sulfur mixture after heat treatment were obtained using $\mathrm{CuK} \alpha$ radiation (D8 Advance, Bruker AXS.).

A Li-S cell was assembled in a 2032-type coin cell configuration shown in Fig. 2. The QSE sheet was sandwiched between the positive electrode and the lithium metal negative electrode of $10 \mathrm{~mm}$ diameter. Discharge-charge characteristics were evaluated by an $8 \mathrm{CH}$ charge/discharge unit (Hokuto Denko Corp.) at $308 \mathrm{~K}$ and $0.05 \mathrm{C}$ in the voltage ranges of $1.8-3.0 \mathrm{~V}$. Here $0.05 \mathrm{C}$ corresponds to $28 \mu \mathrm{A} \mathrm{cm}^{-2}$ on the lithium negative electrode and $84 \mathrm{~mA} \mathrm{~g}^{-1}$ on sulfur, assuming a theoretical capacity of $1672 \mathrm{mAh} \mathrm{g}^{-1}$.

\section{Results and Discussion}

\subsection{Specimens}

\subsubsection{QSEs}

Figure 3 shows typical photographs of the QSE powders with (a) $x=$ 80 and (c) $x=90$, when the cation is DEME, and for QSE sheets of (b) $200 \mu \mathrm{m}$ and (d) $30 \mu \mathrm{m}$ thickness. Although a high concentration of the liquid phase is included in the composite powders, they remain white solid powders as expected from previous studies of the RTIL-Li-salt-fumed silica nanoparticles system [37, 38, 39, 40, 41] and G4-Li-TFSA equimolar complexfumed silica nanoparticles system. [42, 43] As a result of further blending with 5 wt\% PTFE, the composite electrolytes became transparent sheets of 200 $\mu \mathrm{m}$ and $30 \mu \mathrm{m}$ in thickness when $x=80$ and 90 , respectively.

\subsubsection{Positive electrodes}

Figure 4 shows the SEM images of (a) elemental sulfur, (b) AB, (c) KB, and (d) Maxsorb ${ }^{\mathbb{R}}$ powders. Crystalline sulfur, $100 \mu \mathrm{m}$ in diameter, was utilized in this study. The beaded particles of AB and KB had primary grains of $10 \mathrm{~nm}$ diameter. The secondary particle sizes were 5-50 $\mu \mathrm{m}$ and 20-80 $\mu \mathrm{m}$ 
for $\mathrm{AB}$ and $\mathrm{KB}$, respectively.

Figure 5 shows nitrogen adsorption-desorption isotherms of the following powders: (a) AB and AB-S, (b) KB and KB-S, and (c) Maxsorb ${ }^{\circledR}$ and Maxsorb ${ }^{\mathrm{R}}$-S. For all conductive additive-sulfur composites, the adsorbed and desorbed gas concentrations changed. This suggests that the microstructure of the carbon changes by mixing and subsequent heat treatment. Figure 6 shows the pore size distributions of the following powders: (a) AB and ABS, (b) KB and KB-S, and (c) Maxsorb ${ }^{\circledR}$ and Maxsorb ${ }^{\circledR}$-S. For the AB-S composite powder, the concentration of 1-10 nm pores decreased, whereas that of the 10-100 $\mathrm{nm}$ pores increased. The specific surface areas decreased from 120 to $74 \mathrm{~m}^{2} \mathrm{~g}^{-1}$, but the pore volume increased from 0.39 to $0.57 \mathrm{~m}^{3}$ $\mathrm{g}^{-1}$. These results suggest that sulfur is heterogeneously distributed on AB surfaces, and part of the sulfur fills in the 1-10 nm mesopores. For the KB-S composite powder, sulfur appeared to be dispersed in the 10-100 nm mesopores, and thus, the specific surface area and pore volume decreased from 1230 to $990 \mathrm{~m}^{2} \mathrm{~g}^{-1}$ and 3.1 to $2.0 \mathrm{~m}^{3} \mathrm{~g}^{-1}$, respectively. The 1-nm micropores in Maxsorb ${ }^{\circledR}$ are responsible for sulfur dispersion. The specific surface area and pore volume decreased from 2650 to $1770 \mathrm{~m}^{2} \mathrm{~g}^{-1}$ and 1.6 to $1.1 \mathrm{~m}^{3} \mathrm{~g}^{-1}$, respectively.

Figures 7 shows SEM images and distributions of sulfur on positive electrode surfaces containing (a) AB, (b) KB, and (c) Maxsorb ${ }^{\mathrm{R}}$ powders. Figures 7 (d), (e), and (f) show the sulfur distribution in the SEM-analyzed areas relative to the positive electrode containing $\mathrm{AB}, \mathrm{KB}$ and Maxsorb ${ }^{\mathrm{R}}$ powders, respectively. For the positive electrode containing Maxsorb ${ }^{\circledR}$, there were no particles and/or agglomerates on the positive electrode surfaces. The positive electrode containing $\mathrm{AB}$ had larger agglomerates than that containing $\mathrm{KB}$, although XRD patterns for the crystalline sulfur were not observed for either composition. This suggests that not only the specific surface area but also the structure of the conductive additive surface is one of the important factors for the homogeneous dispersion of sulfur in the C-S composite. The correlation between the microstructures of the composite positive electrode and the battery performance is discussed in the following section.

Figure 8 shows a cross-sectional SEM image of the Li-S cell near the 200$\mu \mathrm{m}$-thick QSE and positive electrode interface when the cation is DEME. Lines and cracks in the perpendicular and horizontal directions, respectively, 
appeared because of the scissors used to obtain the cross section. The crosssectional image confirmed that the QSE does not contain open pores. The QSE was attached to the positive electrode, and the positive electrode thickness was approximately $50 \mu \mathrm{m}$.

\subsection{Viscosities and conductivities}

Table 1 summarizes the viscosities and the conductivities of RTILs and RTIL-Li-salt mixtures at $308 \mathrm{~K}$. The apparent conductivities of the 200and 30- $\mu \mathrm{m}$-thick QSE sheets are also summarized. The total conductivity of RTILs decreased with Li-salt dissolution, and the conductivities of RTILs and RTIL-Li-salt mixtures were inversely proportional to viscosity. [50, 51, 52] As summarized in Table 1, the order of conductivity was the same as the inverse viscosity for both RTILs and RTIL-Li-salt mixtures. In addition, the order of the apparent conductivity of the QSEs was the same as the conductivities and inverse viscosities of the RTIL-Li-salt mixtures.[41] The apparent conductivities of the composites were somewhat smaller than the conductivities of the RTIL-Li-salt mixtures. However, the composite maintains liquid-like high ionic conductivities despite the solid-like appearance. Therefore, the performance of the all-solid-state Li-S battery is comparable to the Li-S liquid cells, $[9,24,25,45]$ as discussed below.

\subsection{Discharge-charge capabilities}

Figure 9 shows the initial discharge-charge profiles of the all-solid-state cells using AB, KB, and Maxsorb ${ }^{\circledR}$ as conductive additives at $308 \mathrm{~K}$ and 0.05 C. The 200- $\mu$ m-thick QSE sheet, with the DEME cation, was used for the cell assembly. For the Li-S cells, the apparent initial discharge capacity was $1670 \mathrm{mAh} \mathrm{g}^{-1}$ when Maxsorb ${ }^{\circledR}$ was used. This figure clearly shows that the cell contains a contribution of the electric double layer capacitance (EDLC) because of the surface remaining after sulfur dispersion, i.e., $1770 \mathrm{~m}^{2} \mathrm{~g}^{-1}$ for Maxsorb ${ }^{\circledR}$-sulfur. Therefore, to precisely evaluate the electrochemical response, the contribution of the EDLC was subtracted by assuming a linear relationship between the specific capacity and the voltage. As a result, the discharge capacity was modified to be $1370 \mathrm{mAh} \mathrm{g}^{-1}$. This discharge capacity is greater than the values of the other cells using AB and KB of 990 and $1150 \mathrm{mAh} \mathrm{g}^{-1}$.

The electrochemical reduction of sulfur to $\mathrm{Li}_{2} \mathrm{~S}$ occurs in a stepwise reaction. Although the detailed mechanism is expected to be complicated, $[53,2]$ 
the discharge plateaus are divided into two regions, and the boundary appears at 2.0-2.1 V. In the higher voltage ranges, the reaction can be simplified into $2 \mathrm{Li}+n \mathrm{~S} \rightarrow \mathrm{Li}_{2} \mathrm{~S}_{n}(n \geqq 4)$ while in the lower voltage ones, the reaction can be done into $\mathrm{Li}_{2} \mathrm{~S}_{n}+(2 n-2) \mathrm{Li} \rightarrow n \mathrm{Li}_{2} \mathrm{~S}$. [9, 54, 55] The former and latter reactions predict values of 418 and $1254 \mathrm{mAh} \mathrm{g}^{-1}$, respectively. For the Li-S cells in this study, the initial discharge plateaus were roughly analyzed at 2.3-2.1 $\mathrm{V}$ and 2.1-1.8 $\mathrm{V}$. In the higher voltage plateaus, the initial discharge capacities of the Li-S cells using Maxsorb ${ }^{\circledR}, \mathrm{KB}$ and $\mathrm{AB}$ were determined to be 500,380 , and $430 \mathrm{mAh} \mathrm{g}^{-1}$, respectively. These values are close to the theoretical capacity of $418 \mathrm{mAh} \mathrm{g}^{-1}$, although agglomerates exist in the positive electrode when $\mathrm{KB}$ and $\mathrm{AB}$ are used, as shown in Fig. 5. On the other hand, in the lower voltage plateaus, the initial discharge capacities of the Li-S cells in which Maxsorb ${ }^{\circledR}, \mathrm{KB}$, and $\mathrm{AB}$ were used as conductive additives were 870,690 , and $560 \mathrm{mAh} \mathrm{g}^{-1}$, respectively. The sulfur utilization ratios in the lower voltage region were always lower than those in the higher voltage region regardless of the conductive additive species. This is because the lower voltage region exhibited slower electrochemical kinetics than the higher voltage region. $[9,18,19,26,2]$ These results suggest that a high depth of discharge, i.e., a high sulfur utilization ratio, can be achieved by the high dispersion of sulfur on Maxsorb ${ }^{\circledR}$ with a high concentration of micropores and high specific surface area.

Figure 10 shows the 1-45 cycle discharge-charge profiles of the Li-S cells when the cation is (a) EMI, (b) DEME, and (c) PP13 at $308 \mathrm{~K}$ and 0.05 C. The profiles of the cells using the 200- $\mu$ m-thick QSE sheets are shown in Fig. 10. Similar to the Li-S cell with DEME in Fig. 9, high sulfur utilization ratios were also achieved with EMI and PP13. For EMI and PP13, the EDLC-subtracted initial discharge capacities were 1530 and $1220 \mathrm{mAh} \mathrm{g}^{-1}$, respectively. Figure 11 (a), (b), and (c) show the typical discharge-charge profiles of Li-S cells using the 30- $\mu$ m-thick QSE sheets, with EMI, DEME, and PP13 at $308 \mathrm{~K}$ and $0.05 \mathrm{C}$. The EDLC-subtracted initial discharge capacities for EMI, DEME, and PP13 were 1210, 1100, and $790 \mathrm{mAh} \mathrm{g}^{-1}$, respectively. The order of the initial discharge capacities was the same as the apparent conductivities and inverse viscosities of RTIL-Li-salt mixtures at a constant QSE sheet thickness, as summarized in Table 1. As shown in Figs. 10 and 11, the discharge capacity appeared in the higher voltage is close to the theoretical capacity regardless of the RTIL solvent composition. The dependence of the RTIL solvent composition in the electrochemical reactions 
appeared in the lower voltage region. The order of the EDLC-subtracted initial discharge capacity was the same as that of the apparent conductivity and inverse viscosity. This result suggests that slow ion transport in the QSEs limits the sulfur utilization ratios.

As shown in Figs. 10 and 11, regardless of the RTIL solvent compositions, cells using the thinner electrolytes had smaller initial discharge capacities than those using the thicker electrolytes. It is well known that the slow Liion transport in RTIL-Li-TFSA limits the power density of a cell assembled by using $\mathrm{LiCoO}_{2}$ positive electrode.[56, 41] Ac and de measurements using the Li-symmetric cells also suggest that the contribution of the electrolyte resistance to the total is large. $[46,41]$ The thinner electrolyte reduces the electrolyte resistance, and thus, the sulfur utilization ratio is expected to be enhanced in a thin electrolyte battery. Actually, the sulfur utilization ratio becomes large when the QSEs with the high ion conducting RTIL-Li-TFSA are utilized. However, the dependence of the QSE thickness on the initial discharge capacity is on the opposite of the anticipation that the thinner electrolyte enhances the positive electrode utilization ratios. These results suggest that the ion transport properties in, and the electrochemical reduction process of sulfur near the QSEs are not simple. Further investigations are needed to clarify the effect of the existence of solid surfaces on the battery performance in future work.

The use of QSEs in the Li-S cells with the all-solid-state cell configuration is also validated by not only the large initial discharge capacities but also discharge-charge cycle performances as displayed in Figs. 10 and 11. The composition dependences of RTIL solvents and QSE sheet thickness was also observed in the cycle performances. When $200-\mu \mathrm{m}$-thick electrolyte sheets were used, the discharge capacity retention at the 45 th cycle was $20 \%, 30 \%$, and $25 \%$ for EMI, DEME and PP13, respectively. When the $30-\mu$ m-thick electrolyte sheets were used, the discharge capacity retention was $45 \%$ and $65 \%$ for EMI and DEME, respectively. Of the specimens investigated, the electrolyte with DEME and a 30- $\mu$ m-thick sheet thickness showed the best cycle performance.

There exist preceding works on the development of Li-S battery using RTILs $[24,25,45,26]$ and glyme-Li-TFSA equimolar complexes.[9, 27] The device performances are roughly summarized in the following: 
Yuan etal. investigated the cycling performance of a Li-S half-cell assembled using a PP13-TFSA-Li-TFSA electrolyte and a sulfur-AB positive electrode. The half-cell exhibited capacities of 1050 and $800 \mathrm{mAh} \mathrm{g}^{-1}$ at the initial and 10th discharge, respectively, at a rate of $50 \mathrm{~mA} \mathrm{~g}^{-1}$. The 10th discharge capacity retention was $75 \%$. [24] Wang etal. also examined a Li-S half-cell assembled using an EMI-TFSA-Li-TFSA electrolyte and a sulfurcarbon black positive electrode. They had capacities of 1300 and $600 \mathrm{mAh}$ $\mathrm{g}^{-1}$ for the 1st and 40th discharge, respectively, at a rate of $50 \mathrm{~mA} \mathrm{~g}^{-1}$. The 40th discharge capacity retention was $45 \%$. [25] Rao et al. assembled a Li-S cell using a polymer gel-type electrolyte consisting of the PAN-PMMA with PP14TFSA-Li-TFSA in combination with a carbon nanofiber-sulfur positive electrode. Their Li-S cell has a maximum discharge capacity of $900 \mathrm{mAh} \mathrm{g}^{-1}$ at the 4 th discharge. Then, the discharge capacity degraded to $500 \mathrm{mAh} \mathrm{g}^{-1}$ by the 45th discharge at $167 \mathrm{~mA} \mathrm{~g}^{-1}$. [45] Park etal. assembled the Li-S cell in a 2032-type coin cell configuration using DEME-TFSA-Li-TFSA electrolyte with the comparatively high concentration of sulfur in the composite positive electrode, i.e., $60 \mathrm{wt} \% \mathrm{~S}-30 \mathrm{wt} \% \mathrm{~KB}-10 \mathrm{wt} \%$ poly(vinyl alcohol) (PVA). Their cell exhibited 800 and $650 \mathrm{mAh} \mathrm{g}^{-1}$ for the initial and 50th discharge, respectively, at $303 \mathrm{~K}$ and a rate of $139 \mathrm{~mA} \mathrm{~g}^{-1}$.[26]

Tachikawa et al. have assembled a Li-S cell in a 2032-type coin cell configuration. They used the tetraglyme-Li-TFSA equimolar complex as the liquid electrolyte and a sulfur-inverse opal carbon positive electrode. They confirmed 1100 and $800 \mathrm{mAh} \mathrm{g}^{-1}$ for the initial and the 45th cycles, corresponding to discharge capacity retention of $75 \%$ at $139 \mathrm{~mA} \mathrm{~g}^{-1}$ to sulfur.[9] Dokko etal. assembled the Li-S cells using the equimolar complexes of (triglyme or tetraglyme)-Li-TFSA in 2032-type coin cell. They successfully demonstrated the noticeable discharge-charge cycle performances with a high sulfur concentration in the composite positive electrode, i.e., approximately $60 \mathrm{wt} \% \mathrm{~S}-$ KB-PVA. For the cell using the triglyme-Li-TFSA electrolyte, the initial and the 50th discharge capacities were 1050 and $900 \mathrm{mAh} \mathrm{g}^{-1}$, respectively, at $303 \mathrm{~K}$ and a rate of $93 \mathrm{~mA} \mathrm{~g}^{-1}$. For the cell using the tetraglyme-Li-TFSA electrolyte, the initial and the 50th discharge capacities were 900 and 600 $\mathrm{mAh} \mathrm{g}^{-1}$, respectively, at $303 \mathrm{~K}$ and $139 \mathrm{~mA} \mathrm{~g}^{-1}$.[27]

Since the cell configurations and setup for the measurements including the positive electrode composition, the positive electrode thickness, the elec- 
trolyte thickness, the cut-off voltages, the current density through the electrolyte, and operating temperature are different among the cells listed above, a simple comparison of the cell performances cannot be done. However, the cycling performance and sulfur utilization ratios for the cell assembled using a 30- $\mu$ m-thick QSE with DEME cation validates the applicability of the quasi-solid-state electrolytes in the rechargeable Li-S batteries.

There might be an argument that the noticeable discharge-charge cycle performance is because of the trapping of dissolved lithium polysulfide in the micropores of Maxsorb ${ }^{\circledR}$. [44] However, as revealed by Park etal., the solubility of lithium polysulfide in DEME-TFSA solvents are quite low attributed to the lower donor ability of the solvents.[26] That is, the stable cycle performance of our cell is considered to be essentially caused by the low solubility of lithium polysulfides in the QSE. Less soluble nature of lithium polysulfides in the electrolyte is important to achieve assembling the Li-S battery that allows long term cycle performance and cause no corrosion of metallic lithium.

The above results suggest that the combined use of the QSE containing RTILs and the Maxsorb ${ }^{\mathrm{R}}$-sulfur positive electrode with the all-solid-state cell configuration is effective for achieving better discharge-charge performances at high sulfur utilization ratios.

\section{Conclusions}

In this study, we assembled a Li-S cell using QSEs consisting of RTILLi-TFSA-fumed silica nanoparticles with a bulk-type all-solid-state cell configuration. Transparent electrolyte sheets, 30-200 $\mu \mathrm{m}$ in thickness, were prepared at a RTIL-Li-TFSA volume ratio of $80-90 \%$ by mixing with 5 wt $\%$ PTFE powder. Despite the solid-like appearance, the electrolyte sheets exhibited liquid-like high apparent conductivities. The results from microstructure observation, evaluations of pore distributions, and battery performance indicated that conductive additives with high specific surface areas are effective for the high dispersion of sulfur without any agglomerates via the melting diffusion technique. RTIL solvent composition and electrolyte sheet thickness were further optimized to give superior cycle performance at high sulfur utilization ratios. When the 30- $\mu$ m-thick QSE sheet with DEMETFSA as a solvent was used, our Li-S cell exhibited notable performance. The initial and 45th discharge capacities were 1100 and $690 \mathrm{mAh} \mathrm{g}^{-1}$, re- 
spectively, which are comparable to those of the Li-S cells utilizing mixed RTIL-Li-salt[24, 25, 45, 26] and equimolar complex of glyme-Li-TFSA[9, 27] electrolytes despite of the bulk-type all-solid-state cell configuration.

\section{Acknowledgements}

This study was financially supported by the Adaptable and Seamless Technology Transfer Program (A-STEP) from the Japan Science and Technology Agency (JST), the Funding Program for World-Leading Innovative R\&D on Science and Technology (FIRST), "Innovative Basic Research Toward Creation of High-Performance Battery", and a Grant-in-Aid for Challenging Exploratory Research from the Japan Society for the Promotion of Science (JSPS).

\section{Table caption}

Table 1. Summary of the conductivities and viscosities at $308 \mathrm{~K}$.

\section{Figure captions}

Figure 1. Ion structures of the RTILs: (a) $\mathrm{EMI}^{+}$, (b) $\mathrm{DEME}^{+}$, (c) $\mathrm{PP} 13^{+}$, and (d) $\mathrm{TFSA}^{-}$.

Figure 2. Schematic illustration of the Li-S single-cell configuration.

Figure 3. Typical photograph of the QSE powders with (a) $x=80$ and (c) $x=90$ for the DEME cation. QSE sheets of (b) $200 \mu \mathrm{m}$ and (d) $30 \mu \mathrm{m}$ thickness for $x=80$ and 90 , respectively.

Figure 4. SEM images of the powders of (a) elemental sulfur, (b) AB, (c) $\mathrm{KB}$, and (d) Maxsorb ${ }^{\mathrm{R}}$.

Figure 5. Nitrogen adsorption-desorption isotherms of the powders of (a) $\mathrm{AB}$ and AB-S, (b) KB and KB-S, and (c) Maxsorb ${ }^{\circledR}$ and Maxsorb ${ }^{\mathrm{R}}{ }_{-S}$.

Figure 6. Pore distributions of the powders of (a) AB and AB-S, (b) KB and KB-S, and (c) Maxsorb ${ }^{\circledR}$ and Maxsorb ${ }^{\circledR}$-S. 
Figure 7. SEM images of positive electrode surfaces using (a) AB, (b) $\mathrm{KB}$, and (c) Maxsorb ${ }^{\circledR}$ as conductive additives. (c), (e), and (f) show the sulfur distributions of the analyzed areas by SEM. Yellow circles show the sulfur agglomerates.

Figure 8. Cross-sectional SEM image of the Li-S cell near the QSE and positive electrode interface. The $200-\mu \mathrm{m}$-thick QSE with the DEME cation was used.

Figure 9. Initial discharge-charge profiles of the Li-S cells assembled using $\mathrm{AB}, \mathrm{KB}$, and Maxsorb ${ }^{\circledR}$ as conductive additives at $308 \mathrm{~K}$ and $0.05 \mathrm{C}$. The $200-\mu \mathrm{m}$-thick QSE with the DEME cation was used.

Figure 10. The 1st, 5th, 10th, 20th, and 45th discharge-charge profiles of the Li-S cells for (a) EMI, (b) DEME, and (c) PP13 at $308 \mathrm{~K}$ and $0.05 \mathrm{C}$. The 200- $\mu$ m-thick QSE was used.

Figure 11. The 1st, 5th, 10th, 20th, and 45th discharge-charge profiles of the Li-S cells for (a) EMI, (b) DEME, and (c) PP13 at $308 \mathrm{~K}$ and $0.05 \mathrm{C}$. The 30- $\mu$ m-thick QSE was used. 
Table 1: Summary of the conductivities and viscosities at $308 \mathrm{~K}$.

\begin{tabular}{lllllll}
\hline & RTILs & \multicolumn{3}{c}{ RTIL-Li-salt } & & QSE \\
& & & & & $200 \mu \mathrm{m}$ & $30 \mu \mathrm{m}$ \\
& $\log (\sigma /$ & $\eta /$ & $\log (\sigma /$ & $\eta /$ & $\log \left(\sigma_{\text {app. }} /\right.$ & $\log \left(\sigma_{\text {app. }} /\right.$ \\
RTIL composition & $\left.\mathrm{S} \mathrm{cm}^{-1}\right)$ & $\mathrm{mPa} \mathrm{s}$ & $\left.\mathrm{S} \mathrm{cm}^{-1}\right)$ & $\mathrm{mPa} \mathrm{s}$ & $\left.\mathrm{S} \mathrm{cm}^{-1}\right)$ & $\left.\mathrm{S} \mathrm{cm}^{-1}\right)$ \\
\hline EMI-TFSA & -1.83 & 22.4 & -2.29 & 52.3 & -2.34 & -2.86 \\
DEME-TFSA & -2.29 & 44.2 & -2.82 & 85.0 & -2.87 & -3.15 \\
PP13-TFSA & -2.48 & 76.1 & -3.02 & 232.2 & -3.85 & -3.45 \\
\hline
\end{tabular}

\section{List of references}

[1] R. D. Rauh, F. S. Shuker, J. M. Marston, S. B. Brummer, Formation of lithium polysulfides in aprotic media, J Inorg Nucl Chem 39 (1977) $1761-1766$.

[2] S. S. Zhang, Liquid electrolyte lithium/sulfur battery: Fundamental chemistry, problems and solutions, J Power Sources 231 (2013) 153162 .

[3] Y. Kato, K. Kawamoto, R. Kanno, M. Hirayama, Discharge performance of all-solid-state bettery using a lithium superionic conductor li10gep2s12, Electrochemistry 80 (2012) 749-751.

[4] J. Gao, M. A. Lowe, Y. Kiya, H. D. Abruna, Effects of liquid electrolytes on the charge-discharge performance of rechargeable lithium/sulfur batteries: electrochemical and in-situ x-ray absorption spectroscopic studies, J Phys Chem C 115 (2011) 25132-25137.

[5] S. S. Zhang, New insight into liquid electrolyte of rechargeable lithium/sulfur battery, Electrochim Acta 97 (2013) 226-230.

[6] Y. V. Mikhaylik, J. R. Akridge, Polysulfide shuttle study in the li/s battery system, J Electrochem Soc 151 (2004) A1969-A1976.

[7] X. Ji, K. T. Lee, L. F. Nazar, A highly ordered nanostructured carbonsulphur cathode for lithium-sulphur batteries, Nat Mater 8 (2009) 500506. 
[8] B. Zhang, X. Qin, G. R. Li, X. P. Gao, Enhancement of long stability of sulfur cathode by encapsulating sulfur into micropores of carbon spheres, Energ Environ Sci 3 (2010) 1531-1537.

[9] N. Tachikawa, K. Yamauchi, E. Takashima, J.-W. Park, K. Dokko, M. Watanabe, Reversibility of electrochemical reactions of sulfur supported on inverse opal carbon in glyme-li salt molten complex electrolytes, Chem Comm 47 (2011) 8157-8159.

[10] M. Nagao, Y. Imade, H. Narisawa, T. Kobayashi, R. Watanabe, T. Yokoi, T. Tatsumi, R. Kanno, All-solid-state li-sulfur batteries with mesoporous electrode and thio-lisicon solid electrolyte, J Power Sources 222 (2013) 237-242.

[11] M. Nagao, Y. Imade, H. Narisawa, R. Watanabe, T. Yokoi, T. Tatsumi, R. Kanno, Reaction mechanism of all-solid-state lithium-sulfur battery with two-dimensional mesoporous carbon electrodes, J Power Sources 243 (2013) 60-64.

[12] H. Wang, Y. Yang, Y. Liang, J. T. Robinson, Y. Li, A. Jackson, Y. Cui, H. Dai, Graphene-wrapped sulfur particles as a rechargeable lithiumsulfur battery cathode material with high capacity and cycling stability, Nano Lett 11 (2011) 2644-2647.

[13] L. Ji, M. Rao, H. Zheng, L. Zhang, Y. Li, W. Duan, J. Guo, E. J. Cairns, Y. Zhang, Graphene oxide as a sulfur immobilizer in high performance lithium/sulfur cells, J Am Chem Soc 133 (2011) 18522-18525.

[14] J. Wang, J. Yang, J. Xie, N. Xu, A novel conductive polumer-sulfur composite cathode material for rechargeable lithium batteries, Adv Mater 14 (2002) 963-965.

[15] J. Fanous, M. Wegner, J. Grimminger, A. Andresen, M. R. Buchmeiser, Structure-related electrochemistry of sulfur-poly(acrylonitirile) composite cathode materials for rechargeab;e lithium batteries, Chem Mater 23 (2011) 5024-5028.

[16] T. Kobayashi, Y. Imade, D. Shishihara, K. Homma, M. Nagao, R. Watanabe, T. Yokoi, A. Yamada, R. Kanno, T. Tatsumi, All solidstate battery with sulfur electrode and thio-lisicon electrolyte, J Power Sources 182 (2008) 621-625. 
[17] M. Nagao, A. Hayashi, M. Tatsumisago, Fabrication of favorable interface between sulfide solid electrolyte and li metal electrode for bulk-type solid-state li/s battery, Electrochem Comm 22 (2012) 177-180.

[18] D. Marmorstein, T. H. Yu, K. A. Striebel, F. R. McLarnon, J. Hou, E. J. Cairns, Electrochemical performance of lithium/sulfur cells with three different polymer electrolytes, J Power Sources 89 (2000) 219-226.

[19] B. H. Jeon, J. H. Yeon, K. M. Kim, I. J. Chung, Preparation and electrochemical properties of lithium-sulfur polymer batteries, J Power Sources 109 (2002) 89-97.

[20] J.-H. Yu, J.-W. Park, Q. Wang, H.-S. Ryu, K.-W. Kim, J.-H. Ahn, Y. Kang, G. Wang, H.-J. Ahn, Electrochemical properties of all solid state li/s battery, Mater Res Bull 47 (2012) 2827-2829.

[21] N. Kayama, K. Homma, Y. Yamakawa, M. Hirayama, R. Kanno, M. Yonemura, T. Kamiyama, Y. Kato, S. Hama, K. Kawamoto, A. Mitsui, A lithium superionic conductor, Nat Mat 10 (2011) 682-686.

[22] J. W. Fergus, Ceramic and polymeric solid electrolytes for lithium-ion batteries, J Power Sources 195 (2010) 4554-4569.

[23] J.-W. Choi, J.-H. Kim, G. Cheruvally, J.-H. Ahn, K.-W. Kim, H.-J. Ahn, Microporous poly(vinylidene fluoride-co-hexafluoroprolynene) polymer electrolytes for lithium/sulfur cells, J Ind Eng Chem 12 (2006) 939-949.

[24] L. X. Yuan, J. K. Feng, X. P. Ai, Y. L. Cao, S. L. Chen, H. X. Yang, Improved dischareability and reversibility of sulfur cathode in a novel ionic liquid electrolyte, Electrochem Comm 8 (2006) 610-614.

[25] J. Wang, C. S. Y, Z. W. Zhao, S. Ashraf, D. Wexler, J. Chen, S. H. $\mathrm{Ng}$, S. L. Chou, H. K. Liu, Sulfur-mesoporous carbon composites in conjunction with a novel ionic liquid electrolyte for lithium rechargeable batteries, Carbon 46 (2008) 229-235.

[26] J.-W. Park, K. Yamauchi, E. Takashima, N. Tachikawa, K. Ueno, K. Dokko, M. Watanabe, Solvent effect of room temperature ionic liqudis on electrochemical reactions in lithium-sulfur batteries, J Phys Chem C 117 (2013) 4431-4440. 
[27] K. Dokko, N. Tachikawa, K. Yamauchi, M. Tsuchiya, A. Yamazaki, E. Takashima, J.-W. Park, K. Ueno, S. Seki, N. Serizawa, M. Watanabe, Solvate ionic liquid electrode for li-s batteries, J Electrochem Soc 160 (2013) A1304-A1310.

[28] T. Fukushima, A. Kosaka, Y. Ishimura, T. Yamamoto, T. Takigawa, N. Ishii, T. Aida, Molecular ordering of organic molten salts triggered by single-walled carbon nanotubes, Science 300 (2003) 2072-2074.

[29] T. Katakabe, T. Kaneko, M. Watanabe, T. Fukushima, T. Aida, Electric double-layer capacitors using "bucky gels" consisting of an ionic liquid and carbon nanotubes, J Electrochem Soc 152 (2005) A1913-A1916.

[30] M.-A. Neouze, J. Le Bideau, A. Vioux, Versatile heat resistant solid electrolytes with performances of liquid electrolytes, Prog Solid State Chem 33 (2005) 217-222.

[31] J. Le Bideau, L. Viau, A. Vioux, Ionogels, ionic liquid based hybrid materials, Chem Soc Rev 40 (2011) 907-925.

[32] T. Katakabe, R. Kawano, M. Watanabe, Acceleration of redox diffusion and charge-transfer rates in an ionicn liquid with nanoparticle addition, Electrochem Solid-St 10 (2007) F23-F25.

[33] S. Shimano, H. Zhou, I. Honma, Preparation of nanohybrid solid-state electrolytes with liquidlike mobilities by solidifying ionic liquids with silica particles, Chem Mater 19 (2007) 5216-5221.

[34] U.-H. Lee, T. Kudo, I. Honma, High-ion conducting solidified hybrid electrolytes by the self-assembly of ionic liquids and tio2, Chem Comm (2009) 3068-3070.

[35] M. Mezger, H. Schroder, H. Reichert, S. Schramm, J. S. Okasinski, S. Schoder, V. Honkimaki, M. Deutsch, B. Ocko, J. Ralston, M. Rohwerder, M. Stratmann, H. Dosch, Molecular layering of fluorinated ionic liquids at a charged sapphite (0001) surface, Science 322 (2008) 424-428.

[36] K. Ueno, M. Kasuya, M. Watanabe, M. Mizukami, K. Kurihara, Resonance shear measurement of nanoconfined ionic liquids, Phys Chem Chem Phys 12 (2010) 4066-4071. 
[37] A. Unemoto, Y. Iwai, S. Mitani, S.-W. Baek, S. Ito, T. Tomai, J. Kawamura, I. Honma, Electrical conductivity and dynamics of quasi-solidified lithium-ion conducting ionic liquid at oxide particle surfaces, Solid State Ionics 201 (2011) 11-20.

[38] H. Ogawa, A. Unemoto, I. Honma, Quasi-solid-state lithium-sulfur battery using room temperature ionic liquid-li-salt-fumed silica nanoparticle composites as electrolytes, Electrochemistry 80 (2012) 765-767.

[39] A. Unemoto, Y. Iwai, S. Mitani, S.-W. Baek, S. Ito, T. Tomai, J. Kawamura, I. Honma, Mass transport propoerties in quasi-solidified lithiumion conducting ionic liquids at oxide particle surfaces, Solid State Ionics 225 (2012) 416-419.

[40] S. Ito, A. Unemoto, H. Ogawa, T. Tomai, I. Honma, Application of quasi-solid-state silica nanoparticles-ionic liquid composite electrolytes to all-solid-state lithium secondary battery, J Power Sources 208 (2012) $271-275$.

[41] A. Unemoto, H. Ogawa, S. Ito, I. Honma, Electrical conductivity, selfdiffusivity and electrolyte performance of a quasi-solid-state pseudoternary system, bis(trifluoromethanesulfonyl)amide-based room temperature ionic liquid-lithium bis(trifluoromethanesulfonyl)amide-fumed silica nanoparticles, J Electrochem Soc 160 (2013) A138-A147.

[42] A. Unemoto, T. Matsuo, H. Ogawa, Y. Gambe, I. Honma, Development of all-solid-state lithium battery using quasi-solidified tetraglyme-lithium bis(trifluoromethanesulfonyl)amide-fumed silica nano-composites as electrolytes, J Power Sources 244 (2013) 354-362.

[43] A. Unemoto, Y. Gambe, D. Komatsu, I. Honma, Development of high capacity all-solid-state lithium battery using quasi-solid-state electrolyte containing tetraglyme-li-tfsa equimolar complexes, Solid State Ionics (In Press) doi:10.1016/j.ssi.2013.09.043.

[44] M. Rao, W. Li, E. J. Cairns, Porous carbon-sulfur composite cathode for lithium/sulfur cells, Electrochem Comm 17 (202) 1-5.

[45] M. Rao, X. Geng, X. Li, S. Hu, W. Li, Lithium-sulfur cell with combining carbon nanofibers-sulfur cathode and gel polymer electrolyte, J Power Sources 212 (2012) 179-185. 
[46] J.-W. Park, K. Yoshida, N. Tachikawa, K. Dokko, M. Watanabe, Limiting current density in bis(trifluoromethylsulfonyl)amide-based ionic liquid for lithium batteries, J Power Sources 196 (2011) 2264-2268.

[47] S. Seki, Y. Kobayash, H. Miyashiro, Y. Ohno, Y. Mita, A. Usami, N. Terada, M. Watanabe, Reversibility of lithium secondary batteries using a room-temperature ionic liquid mixture and lithium metal, Electrochem Solid-St 8 (2005) A577-A578.

[48] E. P. Barrett, L. G. Joyner, P. P. Halenda, The determination of pore volume and area distributions in porous sbstances. i. computations from nitrogen isotherms, J Am Chem Soc 73 (1951) 373-380.

[49] R. S. Mikhail, S. Brunauer, E. E. Bodor, Investigations of a complete pore structure analysis i. analysis of micropores, J Colloid Interf Sci 26 (1968) 45-53.

[50] K. Ueno, H. Tokuda, M. Watanabe, Ionicity in ionic liquids: correlation with ionic structure and physicochemical properties, Phys Chem Chem Phys 12 (2010) 1649-1658.

[51] K. Hayamizu, S. Tsuzuki, S. Seki, K. Fujii, M. Suenaga, Y. Umebayaashi, Studies on the translational and rotational motions of ionic liquids composed of n-methyl-n-propyl-pyrrolidinium (p13) cation and bis(trifluoromethanesulfonyl)amide and bis(fluorosulfonyl)amide anions and their binary systems including lithium salts, J Chem Phys 133 (2010).

[52] R. Hagiwara, Y. Ito, Room temperature ionic liquids of alkylimidazolium cations and fluoroanions, J Fluorine Chem 105 (2000) 221-227.

[53] C. Barchasz, F. Molton, C. Duboc, J.-C. Lepretre, S. Patoux, F. Alloin, Lithium/sulfur cell discharge mechanism: an original approach for intermediate species identification, Anal Chem 84 (2012) 3973-3980.

[54] Y. Jung, S. Kim, New approaches to inprove cycle life characteristics of lithium-sulfur cells, Electrochem Comm 9 (2007) 249-254.

[55] Y. Huang, J. Sun, W. Wang, Y. Wang, Z. Yu, H. Zhang, A. Wnag, K. Yuan, Discharge process of the sulfur cathode with a gelatin binder, J Electrochem Soc 155 (2008) A764-A767. 
[56] H. Matsumoto, H. Sakaebe, K. Tatsumi, M. Kikuta, E. Ishiko, M. Kono, Fast cycling of li/licoo2 cell with low-viscosity ionic liquids based on bis(fluorosulfonyl)imide [fsa]-, J Power Sources 160 (2006) 1308-1313. 
(c)

$\mathrm{H}_{3} \mathrm{C}$

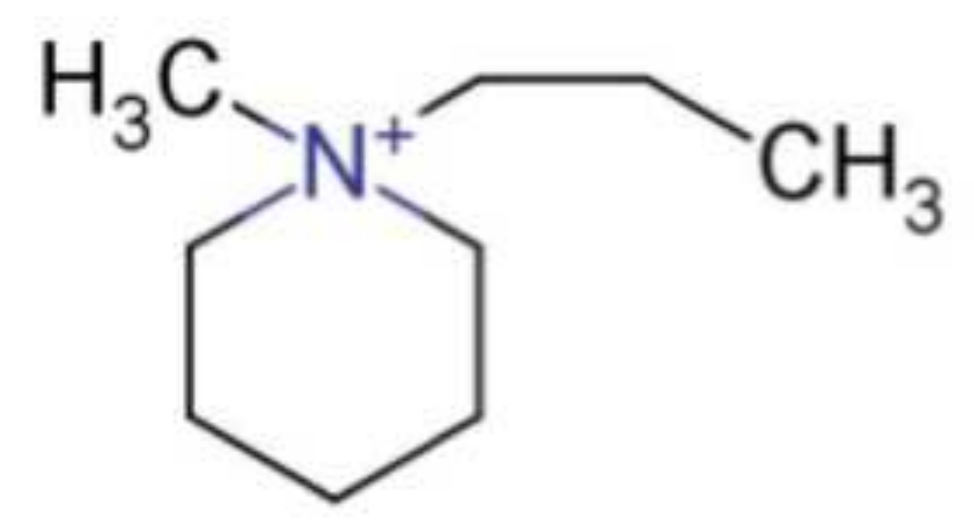

(a) $\quad$ (b)

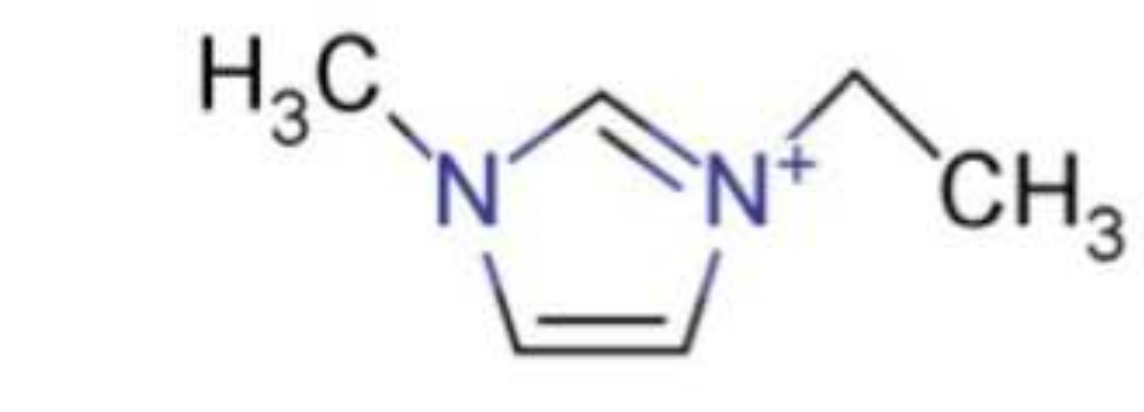

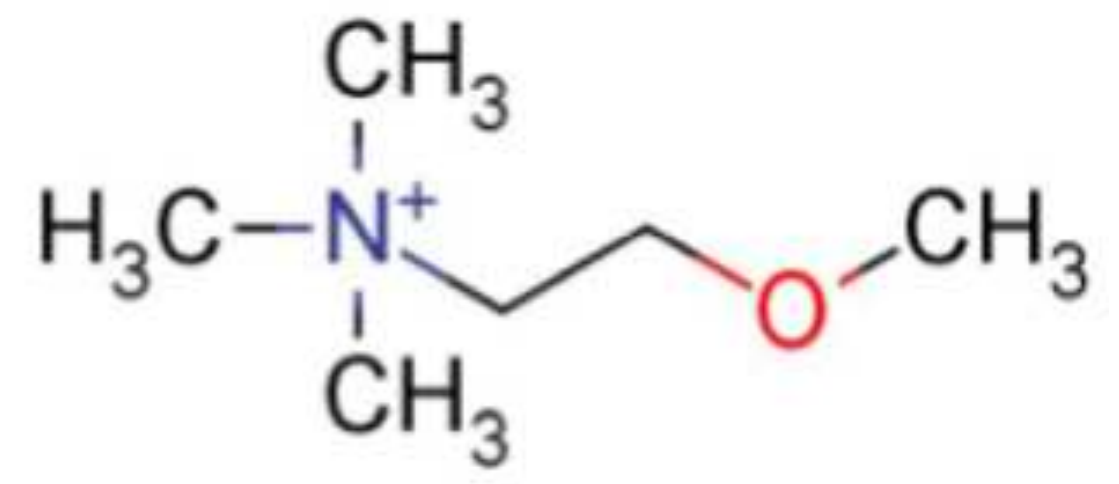

(a) $\quad$ (b)

(d)

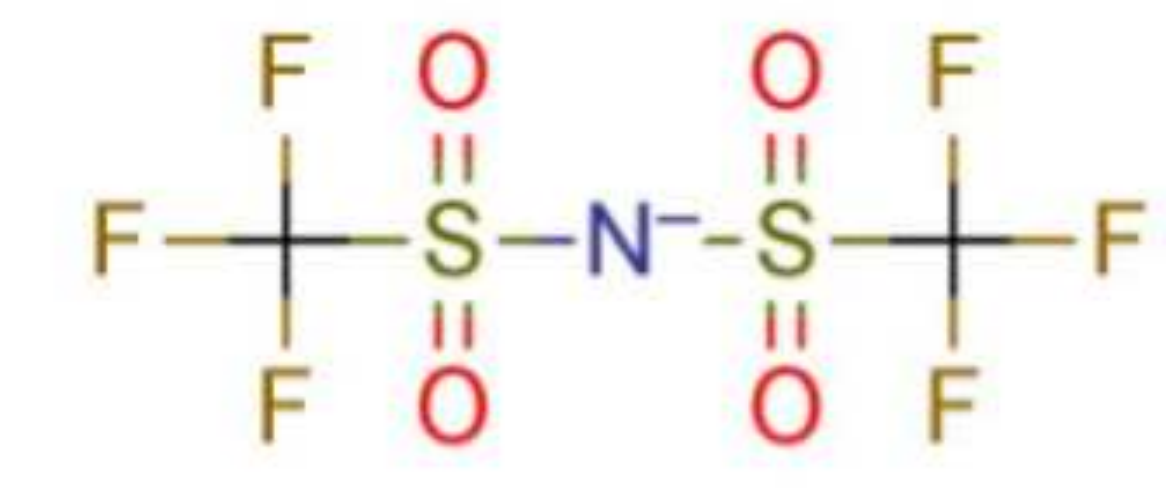


Composite positive electrode

Quasi-solid-state electrolyte or PP separator

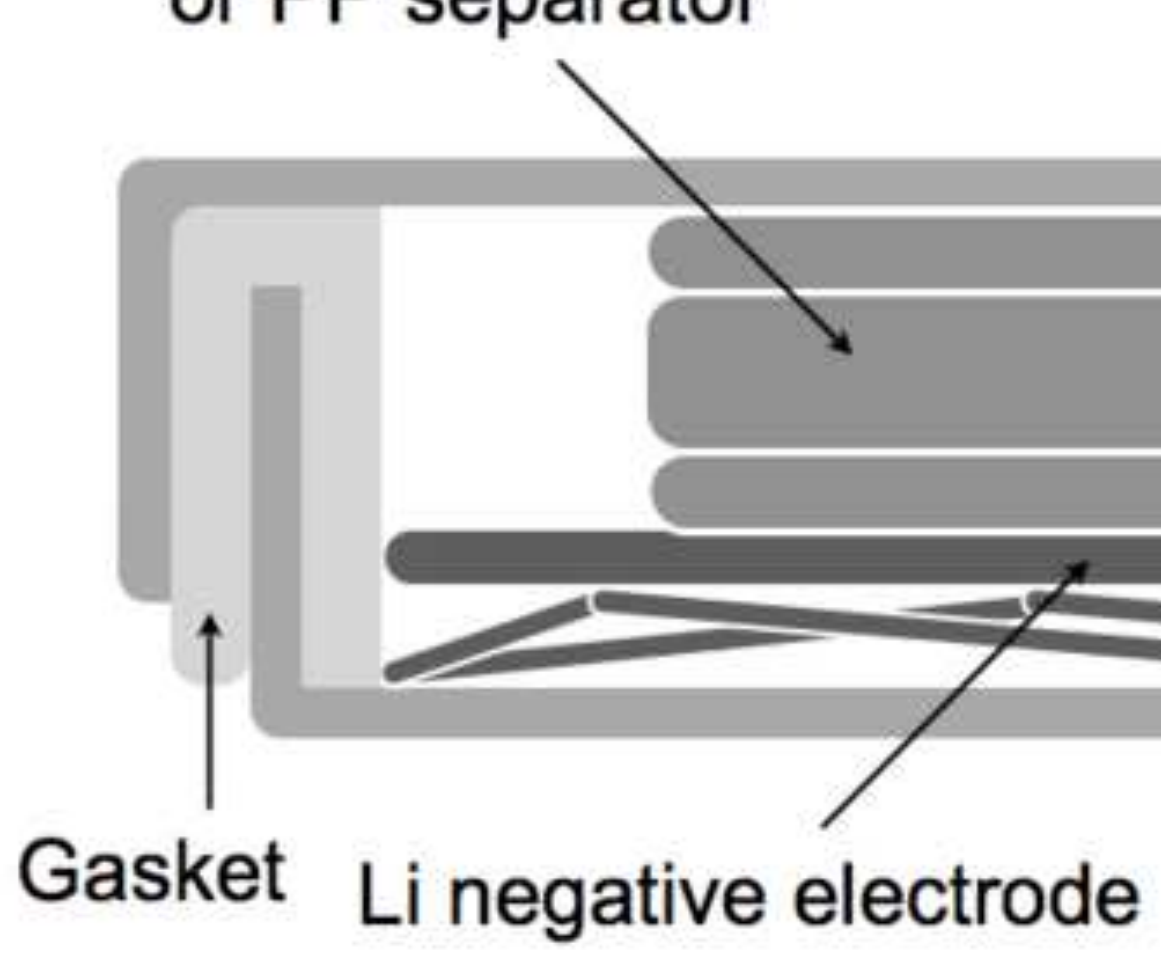

Stainless-steel coin cell vessel

Gasket Li negative electrode 
(a)

sa
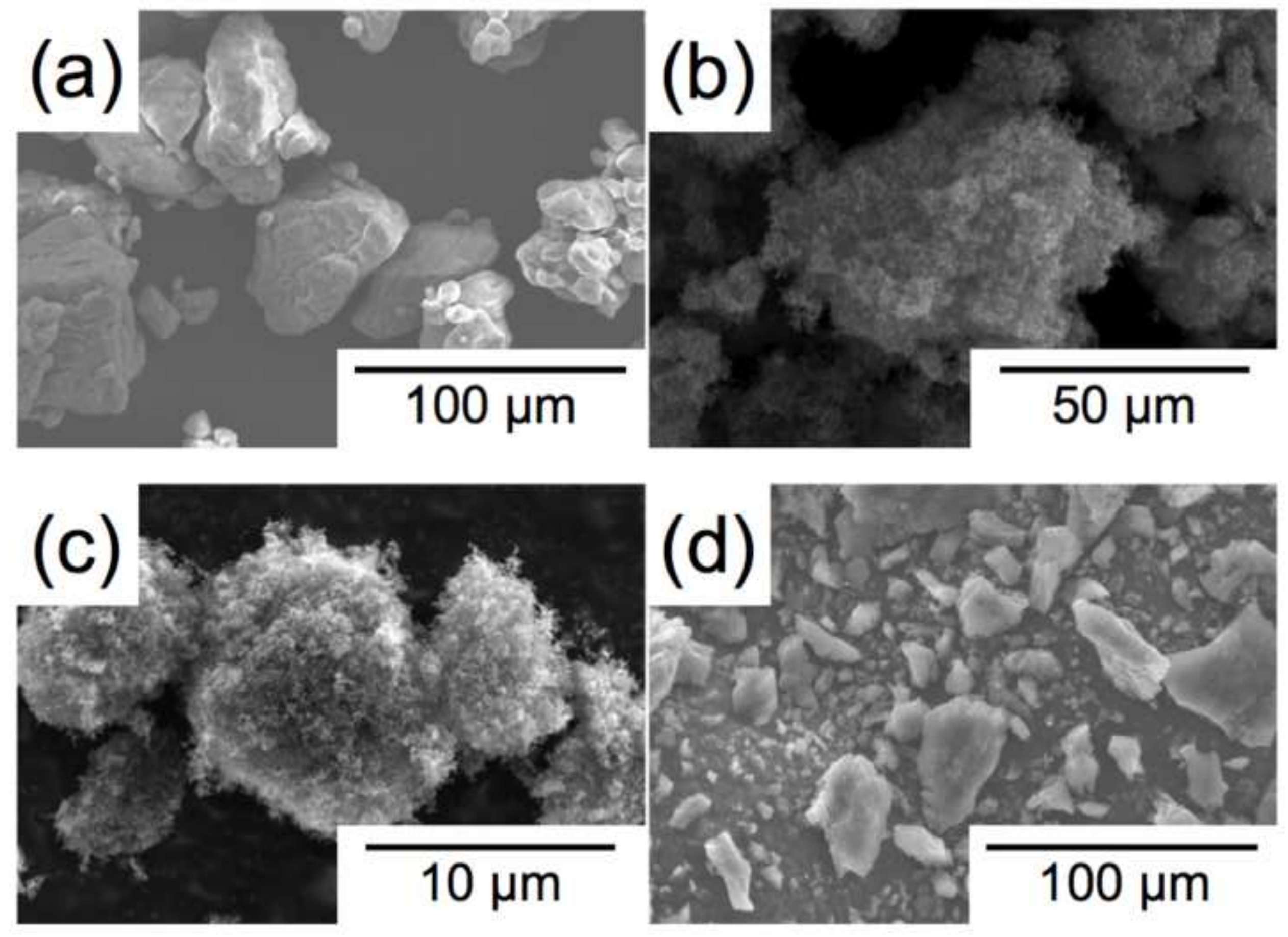

(d)
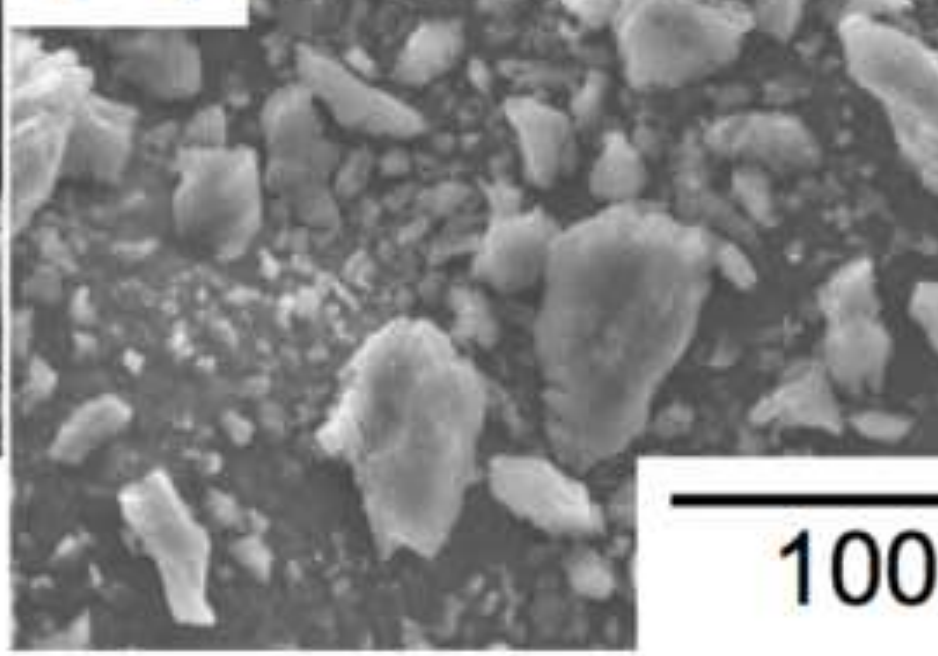

$100 \mu \mathrm{m}$

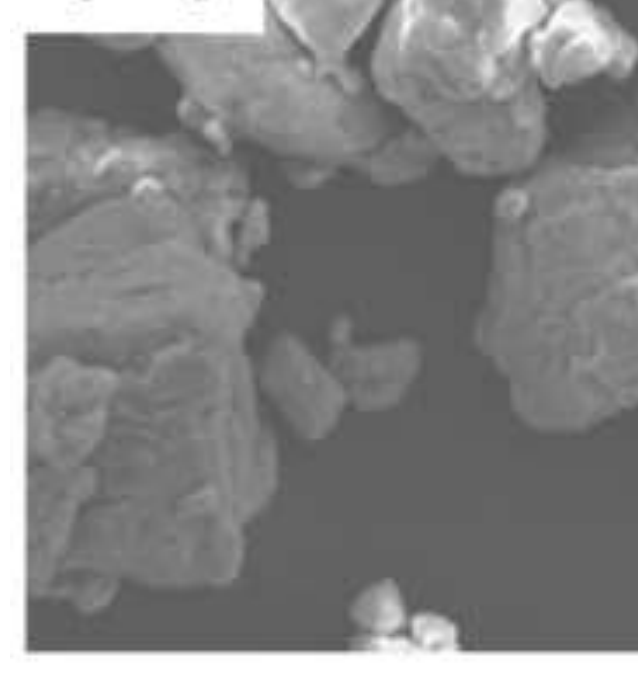

$50 \mu \mathrm{m}$
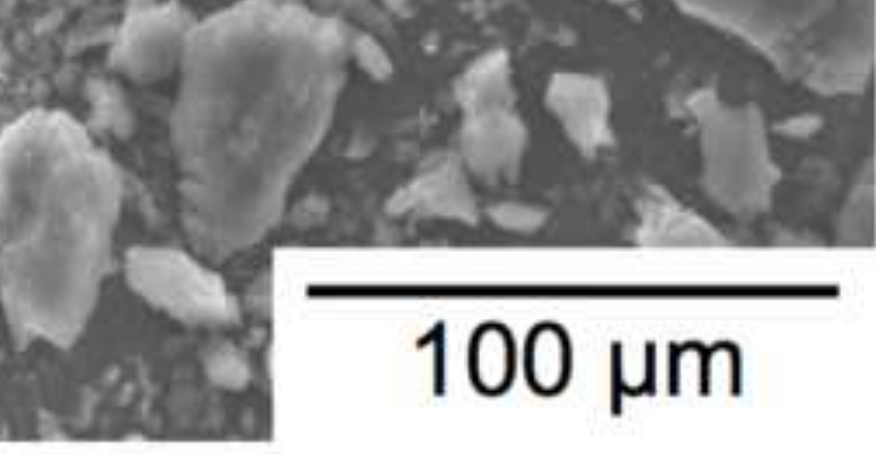

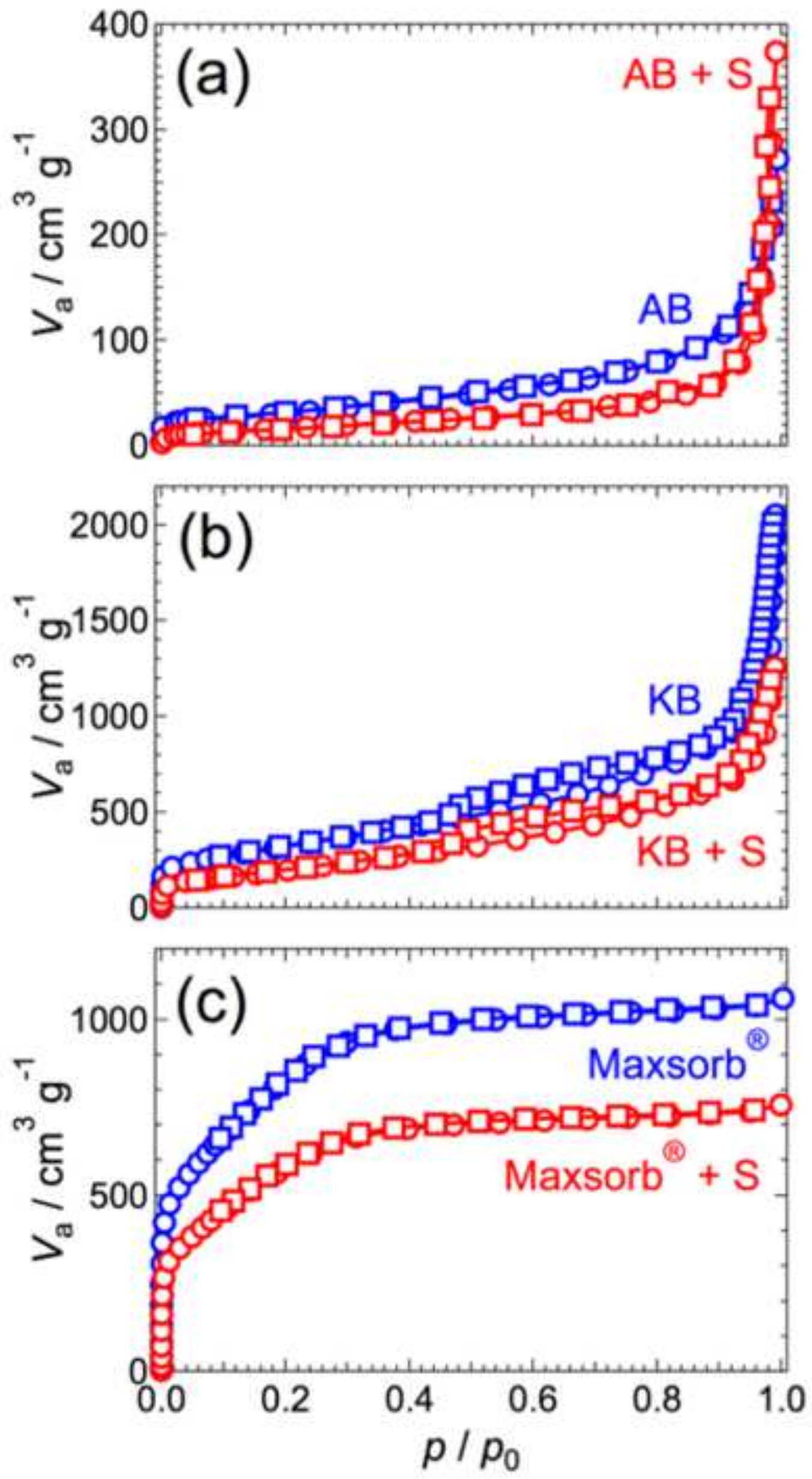

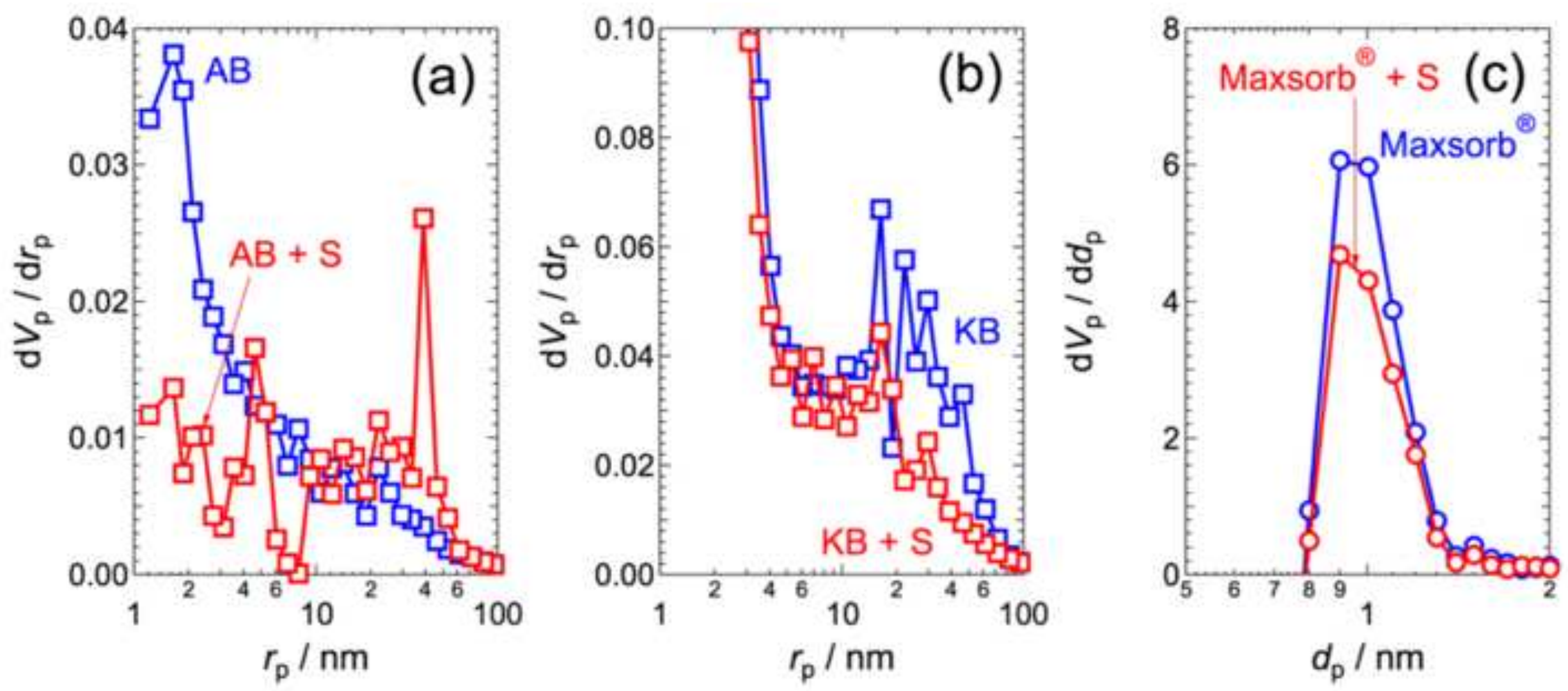

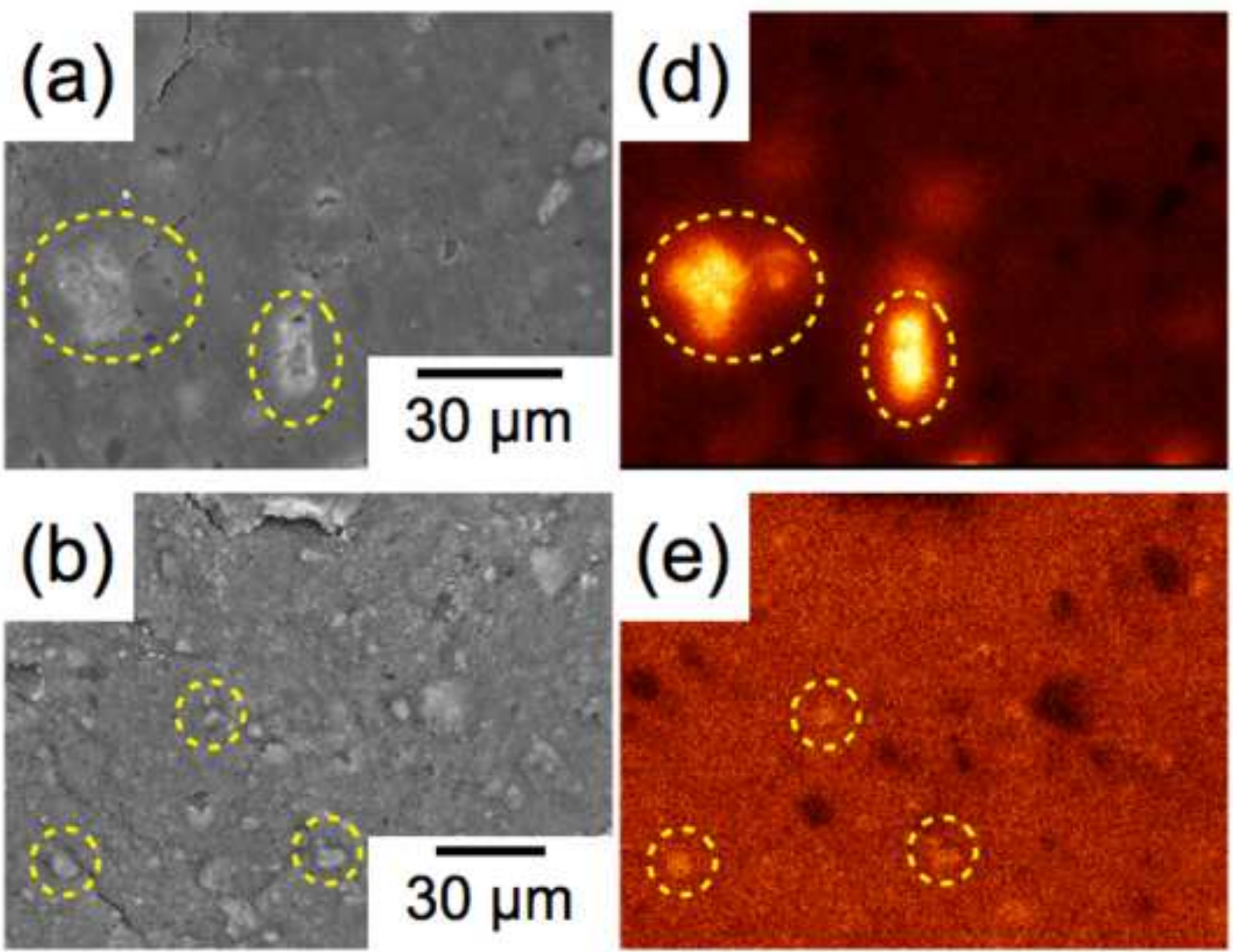

\section{(e)}
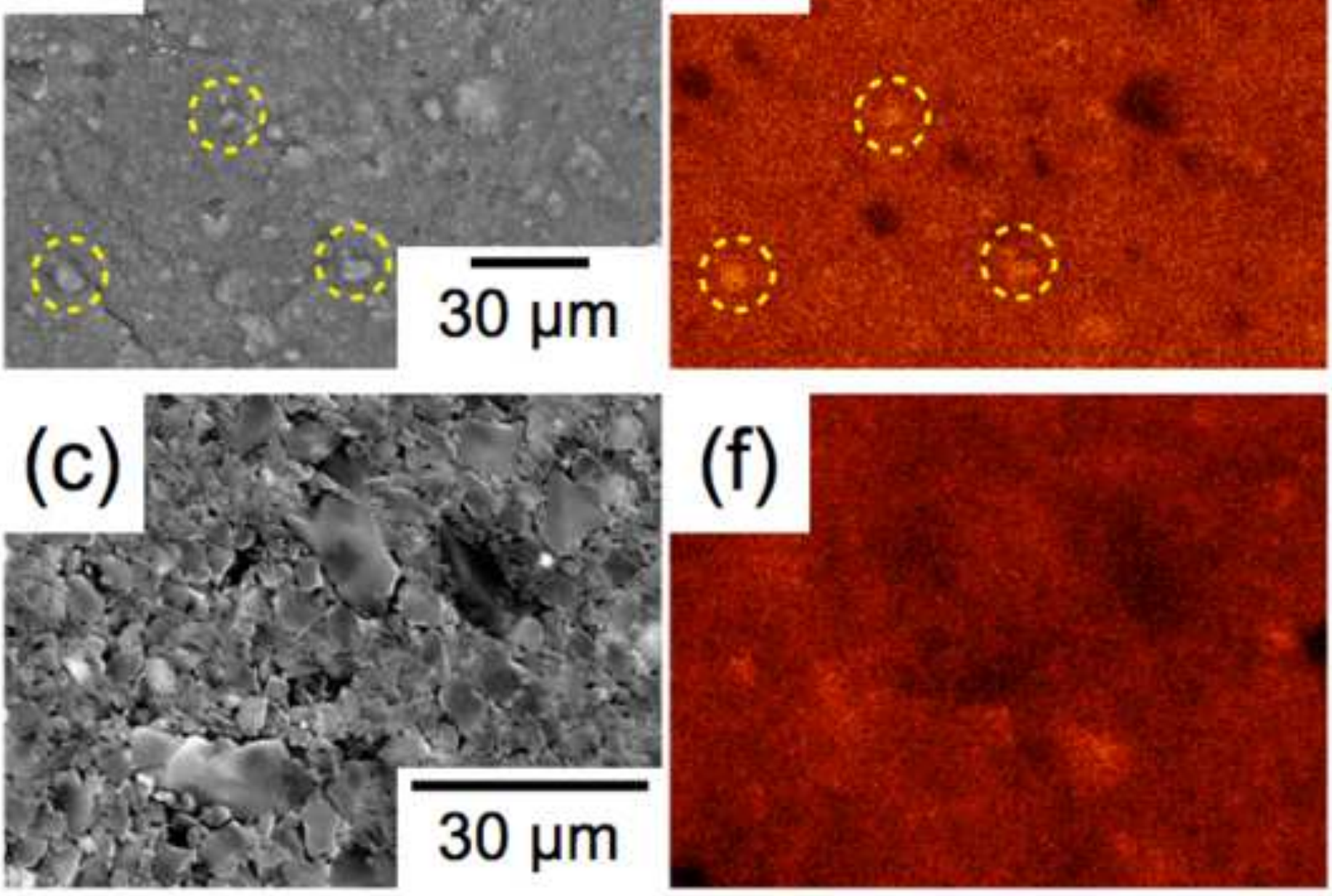

(f) 
Figure10
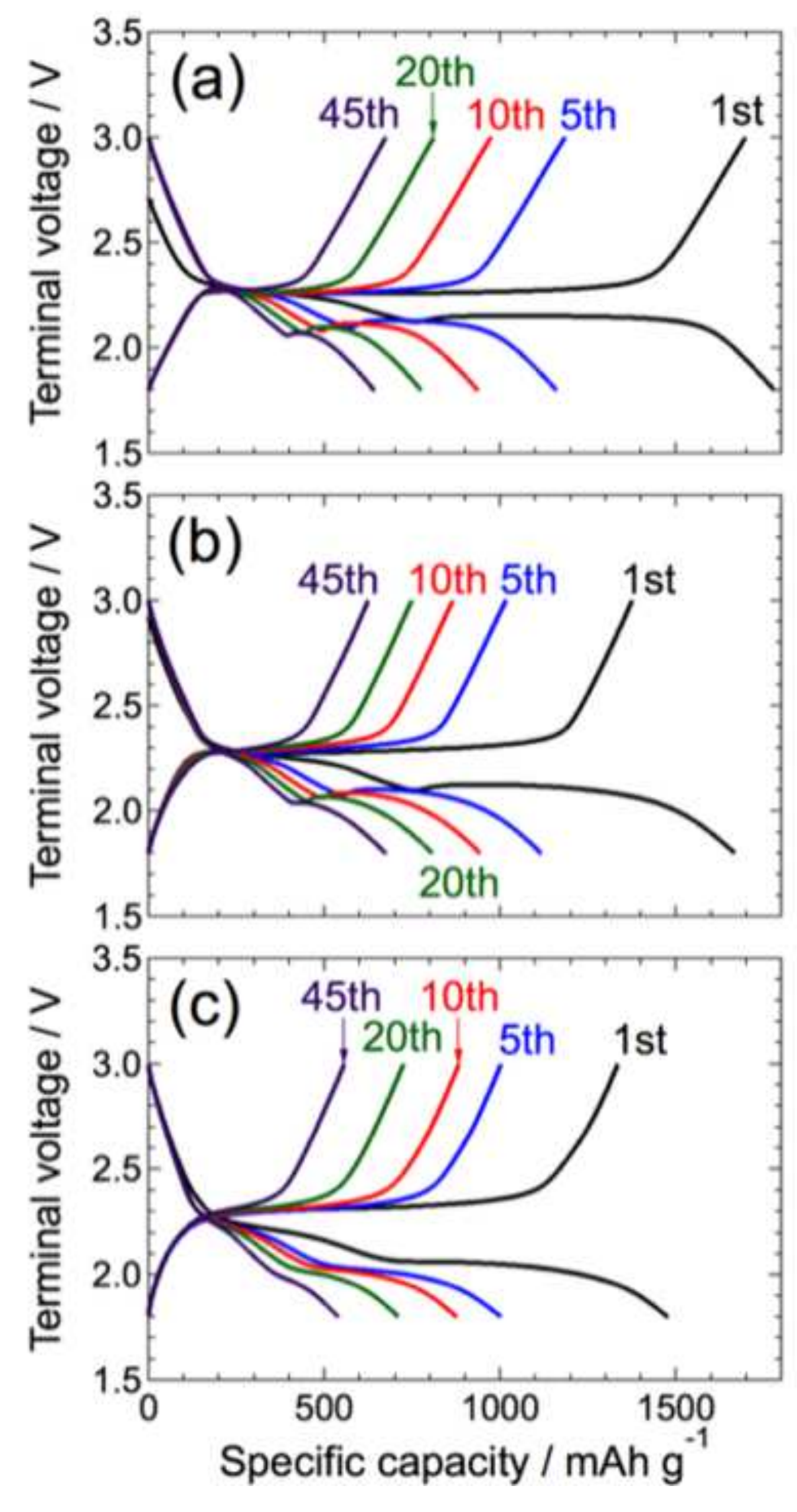

10
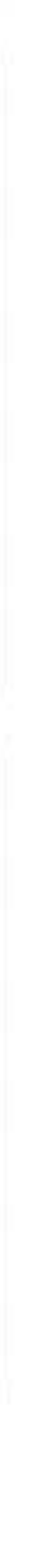

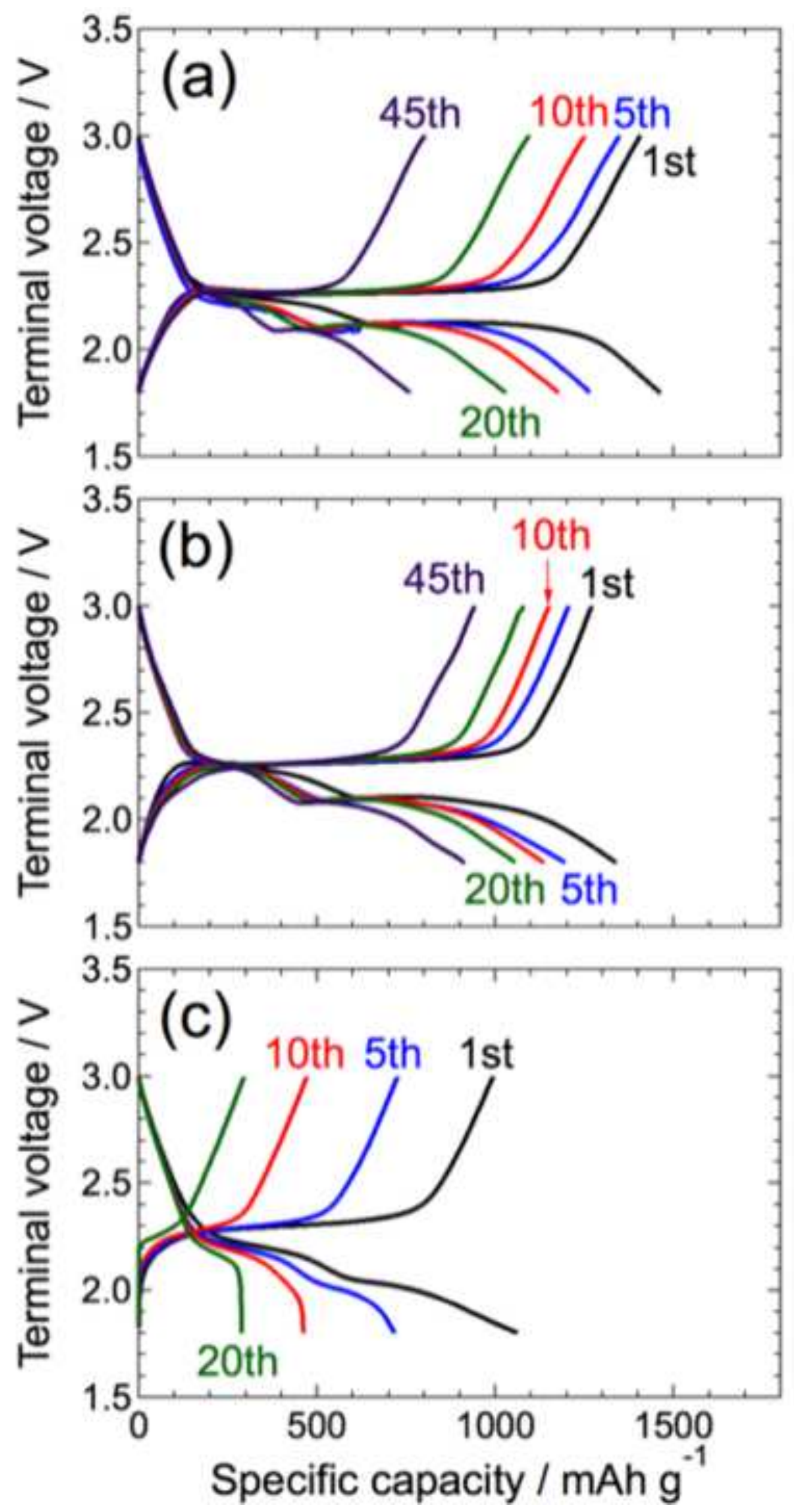